\title{
Questes
}

vestes Revue pluridisciplinaire d'études médiévales

\section{Violences médiévales : introduction}

\section{Léonard Dauphant}

\section{(2) OpenEdition}

\section{Journals}

\section{Édition électronique}

URL : http://journals.openedition.org/questes/349

DOI : 10.4000/questes.349

ISSN : 2109-9472

\section{Éditeur}

Les Amis de Questes

\section{Édition imprimée}

Date de publication : 15 mars 2008

Pagination : 3-7

ISSN : 2102-7188

\section{Référence électronique}

Léonard Dauphant, «Violences médiévales : introduction », Questes [En ligne], 14 | 2008, mis en ligne le 01 janvier 2014, consulté le 24 septembre 2020. URL : http://journals.openedition.org/questes/349 ; DOI : https://doi.org/10.4000/questes.349 


\section{Introduction}

\section{Léonard DAUPHANT}

\section{«Violence médiévale », un concept au coeur du concept ?}

La notion de violence médiévale constitue un problème au sein du concept même de violence : nous devons y affronter le triple obstacle épistémologique de notre propre rapport culturel à la violence et de ses tabous, des préjugés accumulés sur la violence de cet Autre par excellence qu'est l'homme médiéval, d'ici mais d'un temps repoussoir et conjuré, et enfin du rapport problématique qu'entretiennent les sociétés médiévales avec la violence, d'où finalement des sources où la violence est souvent fort présente mais rarement au premier degré. Si la notion de violence est problématisée au Moyen Âge, le terme lui-même n'est guère utilisé en moyen français, sinon dans le sens de viol. Le terme de cruauté est d'un emploi le plus souvent politique, évoquant la tyrannie qui répand le sang (cruor). La plupart des autres mots sont d'un emploi ambivalent, tels «dommaiges» ou «outraiges», qui désignent une atteinte, mais pas forcément violente à notre sens. De même, le terme de « fait» peut être opposé au droit (ainsi « les gens de fait »), ou au contraire valorisé : c'est « le biau fait» des chevaliers. Au Moyen Âge, «ce sont bien les excès de violence qui sont l'objet de condamnations, non la violence elle-même [...] L'originalité de la violence médiévale : elle obéit à un code, et, comme telle, elle ne peut être ni spontanée ni illimitée $»^{1}$. Mais la question est justement ce qui constitue l'excès.

\footnotetext{
${ }^{1}$ Voir Claude Gauvard, Violence et ordre public au Moyen Âge, Paris, Picard, 2005 (Les
} 
Quel est le moment où le «beau fait» devient « outraige», où « rigueur de justice » devient « tyrannie »?

\section{Le tabou de la « violence moderne »}

$\mathrm{Au}$ cœur de notre propre rapport à la violence prévaut sa délégitimation théorique.

La violence est la force illégitime. Selon Claude Gauvard ${ }^{2}$, notre sensibilité pourrait être résumée par cette notion: «la vie humaine doit être sauvegardée à tout prix », qui s'oppose à la vision d'une violence comme «enchaînement de faits nécessaires au maintien de l'honneur ou de la renommée », «moyen de prouver la perfection d'une identité ». Derrière cette distinction réelle, il faut souligner que notre ethos contemporain valorise moins le respect de la vie que le confort : refus de souffrir, de faire souffrir, souvent même de voir souffrir. Or, si la culture médiévale comprend l'honneur, violence intégrée au maintien l'ordre du monde, elle fait également sienne l'appel chrétien au dépassement de soi, la violence de l'ascèse, ne serait-ce que par les jeûnes institutionnalisés. Les deux aspects intègrent parfaitement la violence dans leurs représentations. Même s'ils ne la valorisent pas forcément, ils refusent toujours de la nier. Au contraire, après la violence inhumaine des totalitarismes, dérapage historique d'un Etat ayant monopolisé la violence et la régulation des rapports sociaux, notre tentation est celle du refus théorique de toute légitimité à la violence, d'où de nombreux problèmes pratiques ou hypocrisies. Nous avons heureusement aboli la peine de mort, mais ne savons plus que faire de nos prisons et des détenus qu'on continue d'y mettre.

Par ailleurs, nous avons spontanément du mal à admettre ce que l'anthropologie nous présente du rôle de la violence comme régulation sociale et

médiévistes français 5), introduction, p. 13.

${ }^{2}$ Ibid., p. 12. 
de la concurrence entre les communautés médiévales et l'État naissant pour son contrôle. Ainsi, le titre de l'ouvrage de D. Nirenberg, Communities of Violence, devient après traduction Violence et minorités au Moyen Âge ${ }^{3}$, avec une illustration de couverture suggérant non pas la violence quotidienne des rapports entre voisins de religions rivales, mais un massacre de civils par des soldats. Subrepticement reparaît le refus d'envisager la violence sociale, au profit de l'image assez politiquement correcte d'une violence-oppression, imposée d'en haut, forcément inhumaine et déchaînée.

\section{«Violence médiévale », par définition}

Le concept académique de Moyen Âge est originellemment le temps de la barbarie: sa naissance, notionelle et chronologique, s'enracine dans le mythe des invasions barbares, sa fin nous montre la conjuration de cette violence par l'étude. Entre-temps règnent successivement l'anarchie féodale puis l'obscurantisme religieux et ses persécutions. La violence est fondamentalement médiévale, ou moyenâgeuse. Ce vieux mythe a connu une nouvelle vie récente, en retournant le schéma progressiste sur lequel vit (ou a vécu) notre civilisation : autour de la question de l'origine de l'Holocauste, il ne s'agit de montrer un Moyen Âge conjuré par le Progrès, mais d'en faire le moment (à proprement parler mythique ${ }^{4}$ ) où l'Occident aurait sombré dans l'horreur, devenant «le cancer de l'humanité ».

Nos sources, quant à elles, oscillent entre constatation, justification et

\footnotetext{
${ }^{3}$ David Nirenberg, Communities of Violence, Princeton, Princeton University Press, 1996, trad. fr. Violence et minorités au Moyen Âge, Paris, P.U.F., 2001.

${ }^{4}$ Ibid., Introduction, p. 10 : l'étude de David Nirenberg sur l'Aragon au début du XIV ${ }^{\mathrm{e}}$ siècle a fait largement justice de ce mythe. L'auteur s'oppose nettement au «structuralisme» théorique qui fait remonter au Moyen Âge ce «moment où l'Europe tourne mal » et prépare l'Holocauste. Il s'agit selon lui d'étudier les hommes et les exemples locaux plutôt que des systèmes de pensée qui vivraient de manière autonome sur la longue durée. De même, il ne s'agit pas d'opposer tolérance et intolérance : si la violence est au cœur de la société, c'est qu'il y existe alors une « relation constructive entre conflit et coexistence ».
} 
dénonciation de la violence, à tel point que, les prenant au mot, nous, médiévistes, avons tendance à juger nos époques d'élection beaucoup plus sévèrement que, par exemple, les antiquisants. Dans l'Itinéraire de Paris à Jérusalem, Chateaubriand évoque avec effroi le sac de Rome de 410 et la violence féodale, tout en faisant le dithyrambe de la prise de Carthage par Scipion en 146 avant J.-C. Effet de sources? Tite-Live faisait la louange des soldats romains et du massacre de toute une cité, tandis qu'Augustin et autres sont horrifiés par des actions militaires contemporaines sans doute beaucoup moins violentes.

\section{La violence au Moyen Âge : dénonciations, compromis, compromissions}

Nous sommes en présence d'un paradoxe flagrant dans nos représentations. Le Moyen Âge n'est sans doute pas plus violent que d'autres époques (en dehors des crimes de masse, quel instrument permettra de juger la globalité d'un temps ou d'un lieu?), mais garde une image indélébile de violence. Peut-être parce qu'il invente justement le regard lucide sur sa propre violence. On peut placer le Moyen Âge sous les auspices d'Ambroise de Milan excommuniant l'empereur Théodose après le sac de Thessalonique. Nouveauté radicale : une autorité morale peut condamner le pouvoir temporel, alors même qu'elle le reconnaît comme légitime, pour un acte de violence contre ses sujets : la notion de force illégitime apparait. Cette problématique nouvelle de la légitimité de la violence interne à la société débouche sur un triple rapport complexe à la violence : la capacité à dénoncer la violence; l'intégration des structures violentes de ce monde pour le maintien de l'ordre ou de l'honneur ; enfin l'utilisation de la dénonciation pour imposer sa propre violence.

Ainsi, l'historiographie sur la Paix de Dieu, par exemple, a longtemps été prisonnière de l'alternative entre rapports de force brutaux (l'anarchie féodale) 
et les discours anti-violents des clercs «pacifiques ». Or les plaintes contre la violence peuvent être une arme pour promouvoir de nouveaux rapports de pouvoir au sein d'un groupe social et non forcément une réalité sociale spécifique. Concluons sur ce cas central de l'ambivalence essentielle de la notion de «violence médiévale »: la chevalerie, qui a la brutalité d'une classe dominante, dont la raison d'être est l'action violente, mais dont la justification est le dépassement de la violence, par sa sublimation ou sa condamnation. 